\title{
PATENT GOVERNANCE Y SISTEMA \\ DE PATENTES. PRESUPUESTOS TEÓRICOS \\ DE LA DIMENSIÓN INSTITUCIONAL \\ DE GOBERNANZA
}

\section{ERNESTO GUEVARA FERNÁNDEZ*}

Un estudio de la dimensión institucional y de gobernanza del sistema de patentes ilustrará los desafíos del funcionamiento y operatividad de la protección de las invenciones. La dimensión institucional y de gobernanza integrada al régimen jurídico público transversaliza al sistema de patente, tanto en sus etapas de existencia como en el ejercicio de las posiciones conferidas. La emergencia de nuevos actores y de criterios de global governance y dynamic governance conduce las reformas en curso del sistema, con una incidencia directa en el elemento institucional y las relaciones entre los actores, operadores y sujetos. La presente contribución pretende valorar estos desafíos, como propuesta teórica de aproximación y reinterpretación del derecho de patentes contemporáneo.

\section{NOTAS INTRODUCTORIAS}

Los desafíos de acomodo legal de las tecnologías para el sistema de patentes han sido épicos. Tanto el legislador como las instancias administrativas de examen y concesión y el poder judicial han tenido a su cargo procesos complejos de actualización de elementos vertebradores de la protección mediante patentes. Estos tres actores formales primarios han tenido en los ordenamientos nacionales la responsabilidad de adaptar el sistema de patentes a las demandas tecnológicas en constante evolución, responder a los desafíos crecientes de la ampliación de la patentabilidad, respetar y equilibrar intereses generales y públicos presentes frente

\footnotetext{
* Profesor auxiliar de Propiedad Industrial y Derecho Internacional, Universidad de Oriente (Cuba). Doctorando en Derecho, Universidad de Oriente y University of Antwerp (Bélgica). Máster en Derecho Internacional Público, Universidad de la Habana; máster en Gestión de la Propiedad Intelectual, Oficina Cubana de la Propiedad Industrial. Contacto: ernesto.guevara.fdez@gmail.com Fecha de recepción: 15 de mayo de 2017. Fecha de aceptación: 30 de mayo de 2017. Para citar el artículo: Guevara-Fernández, E. "Patent governance y sistema de patentes. Presupuestos teóricos de la dimensión institucional de gobernanza", Revista La Propiedad Inmaterial n. ${ }^{23}$, Universidad Externado de Colombia, enero-junio 2017, pp. 215-240. DoI: https://doi.org/10.18601/16571959.n23.09
} 
a los derechos exclusivos de explotación del titular, y cumplir los objetivos últimos del sistema de fomentar e incentivar la innovación y generar con ello desarrollo económico y social ${ }^{1}$.

Un desafío adicional del sistema de patentes es que, aun cuando se trate de derechos y títulos jurídicos de eficacia territorial, no quedan aislados los derechos nacionales, sino insertos en una compleja red de relaciones de orden internacional, que convierten a la propiedad intelectual en uno de los regímenes internacionales de mayor armonización. Lo anterior ocurre tanto en el aspecto jurídico, por obra de los tratados internacionales y la naturaleza de sus obligaciones ${ }^{2}$, como en los aspectos extrajurídicos y prácticos: la diseminación de las tecnologías y el conocimiento patentado limitada y/o reforzada por comportamientos de sus titulares, patent tickets y patent trolls, indicadores de organización de las estructuras de $\mathrm{R} \& \mathrm{D}^{3}$, financiación de la investigación, acceso a las tecnologías patentadas en las interfaces con otros objetivos de política como salud pública, o la creación de estándares tecnológicos o patent pools como alternativas, por mencionar algunos tópicos relevantes.

1 Los fundamentos del sistema de patentes han sido avalados in extenso por un acreditado sector de la doctrina. Se sistematizan el incentivo ex ante de la innovación, objetivos de estímulo y promoción del desarollo y la función de herramienta competitiva, todos mediante un especial derecho de explotación en excluisva. En equilibrio con la construcción jurídica de la patente, los basamentos económicos han sido igualemente desarrollados, aportando teorías de naturaleza económica a la existencia de la posición jurídica. Para una visión desde la ciencia jurídica, ver Beier, Friedrich-Karl, "Resultados de la investigación, derecho de patente e innovación”, Actas de Derecho Industrial y Derecho de autor (ADI), 1, 1974, pp. 11-29; Fernández-NovoA, CARlos, "El fundamento del sistema de patente”, en Fernández Novoa, Carlos; Gómez Segade, José A., Hacia un nuevo sistema de patentes. Madrid, 1982, pp. 15-40, Gómez Segade, José Antonio, Tecnología y derecho, Madrid, Marcial Pons, 2000, pp. 265 ss. Junto a esta literatura clásica de nuestra tradición, se incrementa la prodcución de reinterpretaciones téoricas. Para consultarlas, ver Lever, Annabelle (ed.), New Frontiers in the Philosophy of Intellectual Property, Cambridge University Press, 2012; George, Alexandra, Constructing Intellectual Property, Cambridge University Press, 2012; Merges, Robert P., Justifying Intellectual Property, Harvard University Press, Cambridge-London, 2011. Para un estudio de los fundamentos económicos, ver Landes, William M. y Posner, Richard A., La estructura económica del derecho de propiedad intelectual e industrial, trad. Manuel Sánchez Álvarez, Fondo Cultural del Notariado, Madrid, 2006; Penrose, Edith T., La economía del sistema internacional de patentes, trad. Clementina Zamora, Siglo xxi Editores, México, 1974; y con fecha reciente, Guellec, Dominique y Bruno van Pottelsberghe de LA PotTERIE, The economics of the European patent system: IP policy for innovation and competition, Oxford University Press, Oxford, 2007.

2 Ver Correa, C. M., Acuerdo trIPs. Régimen internacional de la propiedad intelectual, Ciudad Argentina, Buenos Aires, 1998, pp. 33-51; sobre el proceso de adopción e implentación en los derechos nacionales, y la relación entre legislación interna y obligaciones internacionales, ver Malbon, Justin; Lawson, Charles y Davison, Mark, The wto Agreement on Trade-Related Aspects of Intellectual Property Rights: A commentary, Edward Elgar, Cheltenham, 2014, pp. 13, 23-46, 390-469.

3 "R\&D" corresponde a Research \& Development, que identifica los procesos de innovación. El empleo más general es de investigación+desarrollo+innovación, en sus siglas $\mathrm{I}+\mathrm{D}+\mathrm{i}$. Refiere los procesos organizativos y de gestión de la actividad de investigación y obtención de productos innovadores, y su protección mediante patentes u otras modalidades de derechos de propiedad intelectual. 
La patente, compleja posición jurídica del titular de los derechos de exclusiva concedidos, opera en un sistema donde la legislación y las políticas afines requieren más que una norma jurídica de depurado diseño técnico normativo. Para lograr que la norma sea eficaz en su sistema regulatorio esta debe tomar el pulso de su contexto socio-económico. Otorgar la patente demanda complejos niveles de interpretación técnica y jurídica, en cumplimiento de los cuales el derecho de patentes debe permitir a los actores un ámbito de actuación que tribute a un sistema flexible y adaptable, sin apartarse de los criterios de seguridad jurídica.

Las revisiones del sistema de patentes en años recientes han puesto la mira en modificaciones de la dimensión institucional y de gobernanza del sistema, en la actividad de los actores del sistema y el empleo de los mecanismos que permitan corregir las distorsiones en el otorgamiento y ejercicio de las patentes. Los movimientos de reforma no se centran en la modificación de estándares sustantivos en busca de convergencia, en la medida en que no se trata de modificar el sistema de patentes, armonizado desde la adopción del Acuerdo sobre los Aspectos de los Derechos de Propiedad Intelectual relacionados con el Comercio (Acuerdo sobre los ADPIC, o TRIPs, por sus siglas en inglés), elemento del paquete constitutivo de la Organización Mundial del Comercio (OMC). De lo que se trata es de emplear otra dimensión, la de gobernanza del sistema de patentes, para diseñar políticas nacionales que contribuyan a la integración de los elementos sustantivos, de observancia y de actuación de los actores del sistema de patentes. El TRIPs ha mantenido un margen de decisión a los Estados por medio de sus autoridades nacionales, al no establecer los mecanismos de funcionamiento del sistema en la organización de la actividad de los actores nacionales, la ratio o indicadores de interpretación que demandan evaluar los criterios sustantivos armonizados. Por lo general, las flexibilidades del TRIPs se señalan en relación con la exclusión de materia patentable, pero es apreciable que no se agota en este aspecto para extenderse a la organización de la actividad de otorgamiento y vigencia y del régimen jurídico público de la patente en sentido general.

Adicionalmente, en este aspecto debe valorarse que el TRIPs ha sido el resultado de complejos procesos de negociación internacional que fraguaron en un consenso, criticable y desequilibrado, pero de referencia para coadyuvar a la mayoría de edad de los actores estatales en la negociación de modificaciones posteriores. Tal aspecto se observa, por ejemplo, en la adopción de la Declaración de Doha y las posteriores reformas propuestas por el artículo 31 bis del TRIPs. En el escenario de la Organización Mundial de la Propiedad Intelectual (OMPI) tampoco parece que se adopte definitivamente un derecho internacional sustantivo de patentes, expresado en un proyecto de Tratado sobre el Derecho Sustantivo de Patentes (sPLT, por sus siglas en inglés) ${ }^{4}$.

\footnotetext{
4 Para mayor información sobre el panorama actual de la armonización sustantiva que se negocia en la ompr ofrecida por la organización internacional, ver: http://www.wipo. int/patent-law/es/harmonization.htm
} 
Los enfoques teóricos recientes permiten revisar el sistema desde su gobernanza, medida de eficacia y funcionamiento, aportando valoraciones sobre los desafíos de su regulación sistémica, la actuación de los actores primarios tradicionales, y el surgimiento de nuevas autoridades con funciones para incidir en la regulación y ejercicio de los derechos de patentes concedidos, a saber, en sus operaciones de explotación. Este panorama va adicionando los desafíos a la visión y concepción tradicional de la patente. Varios modelos teóricos han sido esbozados, basados en la noción de global governance ${ }^{5}$, global governance en materia de conocimiento y propiedad intelectual ${ }^{6}$, gobernanza en red o network governance ${ }^{7}$, nodal governance $e^{8}$, dynamic governance ${ }^{9}$. El común de todos radica en sus renovaciones doctrinales contestatarias frente a la visión funcionalista, administrativista y habitualmente estática del sistema de patentes. El detonante ha llegado con cases law de elevada controversia y polémica: Myriad Genetics ${ }^{10}$ frente a la patentabilidad de genes o AstraZeneca ${ }^{11}$ en las relaciones entre patentes y competencia. En estos han sido

5 Global governance se origina como concepto teórico en el derecho internacional público, sobre todo en las relaciones internacionales. En cuanto regímenes jurídicos internacionales se consideran los aspectos de una materia específica, con elementos normativos fijados en un marco jurídico de tratados, instrumentos jurídicos de distinta naturaleza jurídica, que se acompaña de un andamiaje institucional de organizaciones internacionales y actores internacionales, sujetos o no del derecho internacional público y de las relaciones internacionales. Estos regímenes y escenarios institucionales se erigen como lugares de adopción de decisiones (policy making). Ver Casanovas, Oriol, "La dimensión pública del derecho internacional actual”, en Bouza, Núria; García, Caterina y Rodrigo, Ángel J. (dirs.), Pareja, Pablo (coord.), La gobernanza del interés público global. XXV Jornadas de la Asociación Española de Profesores de Derecho Internacional y Relaciones Internacionales, Barcelona, 19-20 de septiembre de 2013, Tecnos, Madrid, 2015, pp. 57-75. Sobre la noción de governance, ver SANDs, P. H., Lessons learned in Global Environmental Governance, New York, World Resources Institute, 1990, pp. 21 ss.; Juste Ruiz, José y Castillo Daudí, Mireya, La protección del medio ambiente en el ámbito internacional y en la Unión Europea, Valencia, Tirant lo Blanch, 2014, pp. 89-101.

6 Para un estudio ejemplar sobre gobernanza global en materia de propiedad intelectual, ver Drahos, Peter, The global governance of knowledge. Patent Offices and their clients, Cambridge y New York, Cambridge University Press, 2010.

7 Ver Borrás, S., "The Governance of the European Patent System: Effective and legitimate", Economy and Society, vol. 35, n. ${ }^{4}$ 4, 2006, pp. 594, 598.

8 Un estudio detallado de Nodal governance en la propiedad intelectual en Burris, S.; Drahos, P. y Shearing, C., "Nodal Governance”, Australian Journal of Legal Philosophy, vol. 30, 2005.

9 Esta postura teórica es desarrollado por Van Zimmeren y Murray, condensando los modelos previos. Ver Murray, K. y Van Zimmeren, E., Dynamic Patent Governance in Europe and the United States: The Myriad Example, Marquette University Law School, Marquette Law Scholarly Commons Faculty Publications, 2011, pp. 287-342.

$10 \mathrm{El}$ caso Myriad ha marcado en Estados Unidos y en Europa una inflexión en el sistema de patentes. En aspectos sustantivos, ha modificado el estatuto de patentabilidad en Estados Unidos. Sobre este particular, ver Curto Polo, M., "La patentabilidad de las secuencias genéticas en Estados Unidos de América tras la Sentencia del Tribunal Supremo en el asunto 'Association for Molecular Pathology et al. v. Myriad Genetics Inc, et al.' y la incidencia de este pronunciamiento judicial en el ámbito europeo”, Actas de Derecho Industrial y Derecho de autor (ADI), 34, 2013-2014, pp. 493-517.

11 Este caso refuerza las interacciones entre patentes y competencia, al considerar la solicitud de concesión de un derecho de certificados complementarios, realizada de forma abusiva o fraudulenta, como conducta contraria al artículo 102 TFUE. Sentencia del TfUE de 6 de diciembre de 2012. AstraZeneca c. Comisión, C-457/10 P, Rec. 2012, p. I-0000, que desestima el recurso de casación contra la STG de $1 .^{\circ}$ de julio de 2010 (a.T-321/05). 
expuestos varios aspectos: actores emergentes; las relaciones entre actores y sectores de regulación y política; quiebres del sistema administrativo; la necesidad o validación de la participación pública institucionalizada e informal.

El artículo propone una revisión de las dimensiones de la patente como sistema. Cómo impacta la dimensión institucional y de gobernanza en el diseño del sistema, su operatividad y funcionamiento, sería el interrogante de partida. El propósito radicaría en revisar los desafíos del modelo institucional y de gobernanza de la patente, empleando las herramientas teóricas del dynamic patent governance como doctrina en gestación. Se abordan los desafíos para el derecho de patentes en las actuales coyunturas, para ilustrar cómo debe ser atendida la gobernanza del derecho de patentes en un sistema que pretenda sobrevivir, y no ser rezago de una regulación superada por la tecnología y el tiempo.

\section{Dimensiones del sistema de patentes. La variedad de elementos E INTERESES REFLEJADOS EN EL DISEÑO DE LA PATENTE}

El sistema de patentes presenta dimensiones que responden a los fundamentos, fines y objetivos perseguidos por la patente en un ordenamiento jurídico contextualizado por la estructura socio-económica en que opera. Esta pauta conceptual, que no es ni mucho menos aporte propio, es una realidad fáctica que la internacionalización, armonización y replicación en los derechos nacionales de los sistemas de patentes "modelo" en oportunidades relega a un segundo plano.

El sistema de patentes está configurado por dimensiones relevantes en el diseño normativo de la tutela y en el funcionamiento en un contexto socio-jurídico y económico. La clásica distinción fundacional de la patente, entre existencia y ejercicio, ha modulado, por una parte, el contenido público, reflejado en la intervención de la Administración para conceder y extinguir el derecho de patente, junto a los mecanismos procedimentales habilitados para el solicitante y terceras partes en el examen y concesión, y en la vigencia de la patente. Por otra parte, ha permitido identificar una esfera privada, en la que está destinada a surtir efectos la patente en el tráfico jurídico-económico. Los momentos en que operan, con base en la doctrina que distingue entre existencia/adquisición/entitlement y ejercicio/enforcement de la patente centrales de su construcción doctrinal ${ }^{12}$ encuentra

Ver Martín Aresti, P., "Capítulo 15. Derecho antitrust y protección de los bienes inmateriales”, en García-Cruces, J. A. (coord.), Tratado de derecho de la competencia y de la publicidad, vol. 1, Valencia, Tirant lo Blanch, 2014, pp. 1005 ss.; Conde Gallego, BeAtriz, "La política de competencia en el sector farmacéutico: nuevos desafíos para la relación entre los Derechos de propiedad industrial y el Derecho de competencia”, Actas de Derecho Industrial y Derecho de Autor (ADI), 31, 2010-2011, pp. 63-66.

12 En el estudio de las patentes en su estructura interna. Van Overwalle se refiere a la distinción entre etapas como "foundational distinction between existence/exercise of patent rights". Ver Van Overwalle, G., "Policy Levers Tailoring Patent Law to Biotechnology: Comparing U.S. and European Approaches", UC Irvine Law Review, vol. 1, n. ${ }^{\circ} 2,2011$, p. 443 . 
referentes y confirmación jurisprudencial ${ }^{13} \mathrm{y}$ doctrinal. A efectos de garantizar la gobernanza del sistema, y las posibilidades de dinamizar los mecanismos y autoridades y actores del sistema, como se verá, este tema es relevante, en la medida en que la concesión modula las etapas ex ante o pre-grant, y ex post o post grant, los dos momentos ordinales en el iter de la patente.

La distinción de la patente entre lo público y lo privado, entre existencia y ejercicio, no resulta satisfactoria, en vistas de las complejas interacciones y las realidades de la vida de la patente. En la visión de sistema, los límites y predios de estas se han desdibujado, si es que alguna vez existieron, complicando el panorama de funcionamiento y eficacia para alcanzar los fines de política perseguidos por el sistema, también fundacionales. La reinterpretación de estos objetivos y propósitos sirve de referente para redimensionar el sistema de patentes.

La dimensión pública se expresa en las herramientas de regulación e intervención pública, y en las relaciones jurídicas entre los sujetos ${ }^{14}$ involucrados en la solicitud, concesión y existencia de la patente, o sea, en todo el iter de la patente. La dimensión pública no se limita a la regulación normativa, que funcionaría como un elemento común, pero su origen de acto legislativo lo coloca en la actuación pública que da origen al sistema. Diferentes comportamientos y exigencias se despliegan en los estadios, etapas o estados legales, a lo largo de la vida de la patente ${ }^{15}$. El iter de la patente en el sistema opera como una línea de tiempo donde se suceden situaciones legales y subjetivas, donde los actores y sujetos se ven movilizados por los requerimientos normativos, en sede sustantiva y procedimental, desde la solicitud hasta la expiración de la validez del título concedido. Estos dos extremos son variables, pues el otorgamiento de la patente es solo el perfeccionamiento en predios del sistema para la protección de la idea patentable previa, que opta o no

13 Por la jurisprudencia de raigambre europea se ha acudido a la distinción entre existencia y ejercicio de las patentes que sirve de referente en este artículo. Su empleo brindó referentes de compatibilidad entre los sectores normativos de propiedad intelectual y derecho de la competencia. Legalmente se utilizó para la aplicación de las prohibiciones de los artículos 85 y 86 del Tratado de Roma, actuales artículos 101 y 102 Tfue, a negocios jurídicos y conductas en que se involucraba un derecho de propiedad intelectual de origen nacional. Ver Martín Aresti, "Capítulo 15. Derecho antitrust", cit., pp. 1005 ss.

14 Cuando se refiere a los sujetos, se considera solo a los que toman parte en las relaciones jurídicas expresamente configuradas por el ordenamiento en sede de patentes. Sujetos serían el solicitante y/o titular, la autoridad concesional administrativa, y los terceros, siendo múltiples las relaciones jurídicas que se configuran. De igual forma, las relaciones entre el titular y terceros tiene un basamento administrativo, pero solo operan en el ámbito privado en caso de infracciones. En el caso de las operaciones de licenciamiento de patente, los contratos definen sus elementos subjetivos, y no son estos fijados por la legislación de patentes.

15 El ordenamiento prevé niveles de tutela distintos, criterio que proviene de la postura doctrinal que distingue entre derecho de inventor, derecho a la patente, derechos de patente, refiriendo el alcance de la protección y el efecto que comportan, a saber, el perfeccionamiento del derecho del creador en los predios del sistema de patentes. Ver Massaguer fuentes, J. y Massaguer Fuentes, José, Los efectos de la patente en el comercio internacional, Barcelona, Bosch, 1989, pp. 31-42; FERnández Rodríguez, CArmen, Propiedad industrial, propiedad intelectual y derecho administrativo, Madrid, Dykinson, 1999 , p. 54. 
por buscar protección; la duración de la patente marcada por la eficacia temporal de al menos 20 años puede quedar truncada por la manifestación de ciertas causales de terminación del derecho, a saber, nulidad, caducidad, o extenderse como monopolios de facto ${ }^{16}$ o derechos complementarios ${ }^{17}$, la posición en el mercado del titular de la patente. Además, en el iter de la patente, que opera en una etapa de existencia y en una esfera de ejercicio, pueden manifestarse, sobre todo en la segunda, de ejercicio y tráfico jurídico de la patente en las relaciones comerciales, distorsiones que puede, ex post, enfrentar el sistema de patentes mediante sus propias instituciones y herramientas; véanse los límites a los derechos exclusivos del titular, o el régimen de las licencias obligatorias. En resumen, en el iter de la patente, a lo largo de los diversos estados legales de la patente y la vida de la misma, tienen lugar, con mayor o menor intensidad, procedimientos, acciones, recursos, sustantivos y de derecho adjetivo, que integran la dimensión jurídico-pública del sistema de patentes y no se limitan a la existencia, sino que se extienden también al ejercicio de la patente en sede privada.

En sentido técnico jurídico, la dimensión pública de la patente se encargaría ex ante de las formas de intervención pública mediante las cuales la patente se configura, esto es, en que se manifiesta la existencia de la patente como posición jurídica, habilitando para el ejercicio del catálogo de derechos consagrado en el ius prohibendi; así como de las instituciones, mecanismos y herramientas ex post de corrección de distorsiones y terminación del derecho en su etapa de ejercicio, mediante todo un régimen jurídico público destinado a ser gestionado por los actores formales y operadores del sistema.

En cuanto a la dimensión privada de la patente, se integra por las instituciones y mecanismos propios del ejercicio de la patente por sus titulares, como objeto del tráfico jurídico. Las múltiples posibilidades de realización con que contaría el titular, expresada en los más variados esquemas prestacionales contractuales ${ }^{18}$, los institutos de trasmisión inter vivos o mortis causa, ilustran la dimensión de la patente en sede iusprivatista. No puede desconocerse que la patente, asegurada en la esfera pública y condicionada por peculiares mecanismos de intervención de la Administración, es sin embargo un derecho destinado a surtir efectos en la esfera de las relaciones privadas. La patente deviene apta para constituirse como objeto de negocios jurídicos de la más diversa naturaleza, contenido y formalidades. Ocurre

16 Mediante licencias de paquetes de patentes con fecha de caducidad diferida, o mediante contratos de licencias de know-how sobre conocimientos técnicos indispensablers para explotar la patente.

17 Es el caso, por ejemplo, de los certificados complementarios de protección de medicamentos y productos fitosanitarios en Europa. Para un estudio ilustrativo, ver Botana Agra, Manuel, "Capítulo xix. Los certificados complementarios de protección de medicamentos y productos fitosanitarios", en Fernández-Novoa, Carlos; Otero Lastres,

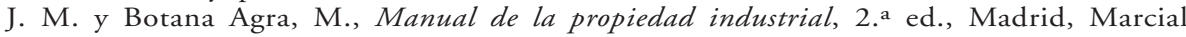
Pons, 2013, pp. 323-333.

18 Para un estudio detallado sobre la patente en la esfera privada de ejercicio desde los esquemas contractuales de licencia, ver Martín Aresti, Pilar, La licencia contractual de la patente, Pamplona, Aranzadi, 1997. 
eso, por su "condición de posición jurídica dotada de valor patrimonial"19. En esta esfera pueden manifestarse, asimismo, distorsiones al sistema que deben ser corregidas expost mediante los institutos propios del sistema, o por mecanismos externos.

En la dimensión pública, se propone destacar la autonomía creciente de los aspectos institucionales y de gobernanza, basados en el criterio de garantizar el funcionamiento del sistema de patentes. La dimensión institucional y de gobernanza se enfocaría en el diseño de sus actores ${ }^{20}$ y operadores ${ }^{21}$, y en las funciones y roles de estos en el sistema para cumplir con los requerimientos de la patente. Otro elemento por considerar sería la naturaleza de las relaciones, sustituyendo la visión jerárquica y de subordinación basada en relaciones jurídico-administrativas por relaciones colaborativas y fluidas entre actores en diferentes planos. Los modelos organizacionales estáticos basados en relaciones ordenadas por la autoridad administrativa de examen y concesión de la patente, bajo enfoques de gobernanza dinámica y emergencia de nuevos actores, exigen relaciones horizontales de colaboración con actores distintos a las autoridades. Ofrece avenidas de interacción con actores distintos de las autoridades de examen y concesión en la consecución de los fines del sistema de patentes, en relaciones horizontales de colaboración. Entre los ejemplos de relaciones horizontales se encuentran los casos de colaboración entre oficinas de patentes de diversos países, en los denominados trilaterales o Trilaterals entre las oficinas de patentes de Estados Unidos (USPTo) ${ }^{22}$, Japón (JPO) ${ }^{23}$ y la Oficina Europea de Patentes (European Patent Office, EPo) ${ }^{24}$. Otro ejemplo similar es el Asian Trilaterals formado por las oficinas de China ${ }^{25}$, Corea del Sur ${ }^{26}$ y Japón ${ }^{27}$. El caso más universal es el procedimiento de solicitud internacional establecido en el Tratado de Cooperación en Materia de Patentes (Patent Cooperation Treaty, PCT) ${ }^{28}$,

19 Martín Aresti, Pilar, “Capítulo xv. Transferencias, licencias y gravámenes”, en Bercovitz Rodríguez-Cano, Alberto (dir.), La nueva Ley de Patente. Ley 24/2015, de 24 de julio, Cizur Menor, Thomson Reuters-Aranzadi, 2015, p. 350.

20 Los actores refieren a todos los intervinientes en el sistema de patentes, con diferentes roles, propósitos y posiciones.

21 La referencia a los operadores del sistema de patentes, en el ordenamiento jurídico, indica los destinatarios de la norma jurídica, o sea, a quiénes está dirigida la aplicación del cuerpo legal en concreto.

22 United States Patent and Trademark Office.

23 Japanese Patent Office.

24 The Trilateral Co-operation, inicado en 1983, establece un mecanismos colaborativo de cooperación, mediante intercambio de examinadores y procesamiento por vía PCT que alcanza cerca del $70 \%$ de las solicitudes y patentes concedidas a nivel mundial. Para información sobre el mecanismo, ver: http://www.trilateral.net/index.html Información estadística detallada de las patentes concedidas en los reportes anuales, disponible en: http://www.trilateral.net/statistics/tsr.html

25 State Intellectual Property Office (sipo) of China.

26 Korean Intellectual Property Office (KIPO).

27 Drahos los califica como "horizontal processes of learning and reciprocal coordination among the big developed-country offices". Para un estudio a profundidad y crítico, ver Drahos, The global governance, cit., pp. 177-220.

28 El рСт permite un procedimiento de presentación de solicitudes para el que cumplen las funciones de Administración encargada de la búsqueda internacional las oficinas de Australia, Austria, Brasil, Canadá, China, España, Estados Unidos, Rusia, Finlandia, Israel, Japón, Corea, Suecia, la Oficina Europea de Patentes y el Instituto Nórdico de 
como procedimiento que instaura un examen preliminar internacional que permite al solicitante diferir la autoridad de examen a una oficina designada, nacional o regional, que da paso en la fase de concesión a las autoridades nacionales respetando el criterio de territorialidad que ordena la protección mediante patentes. En este mecanismo se comparten funciones entre la autoridad de examen y la autoridad de concesión, siendo un caso que quiebra los esquemas tradicionales de relaciones jurídico-administrativas domésticas.

En la dimensión institucional y de gobernanza se diseñan las relaciones jurídicas entre los actores del sistema, legitimando y asimilando la actuación de actores y sujetos, primarios, secundarios y no tradicionales. Las relaciones con la dimensión pública serían notorias, en la medida en que la gobernanza, que brindaría la operatividad y funcionamiento del sistema, encontraría en el régimen jurídico público muchos de los elementos esenciales para su empleo. El régimen jurídico público de la patente, establecido en la legislación, ofrecerá los mecanismos y herramientas de intervención pública, que se complementan e interactúan con la dimensión de gobernanza e institucional. En sentido general, la dimensión jurídico-pública comprendería estos elementos: la organización de los actores, las relaciones entre estos y los mecanismos legales de funcionamiento del sistema. La dimensión de gobernanza e institucional brinda posibilidades de reinterpretación de estos mecanismos de intervención pública para garantizar el equilibrio de intereses públicos y privados perseguidos por el sistema.

La gobernanza, como criterio, no se concibe limitada a la actividad administrativa basada en relaciones jerárquicas y de subordinación. Sin desconocer el papel de la autoridad de concesión y examen, una de las variadas personificaciones administrativas en el sistema de patentes, se reivindica la condición de actores y sujetos, los primeros como intervinientes en el sistema y los segundos como elementos personales de las relaciones jurídicas diversas que se manifiestan en el iter de la patente, donde oficinas de patentes, solicitantes y/o titulares, y terceros, toman parte.

\section{Patent governance Como Criterio doctrinal. Incidencia}

EN LAS CARACTERÍSTICAS DEL SISTEMA DE PATENTES

Las principales reformas en curso al sistema de patentes han asumido como criterio ordenador la noción de patent governance. Al menos en la experiencia europea ${ }^{29}$,

Patentes. El рст cuenta a la fecha con 152 Estados parte contratantes.

29 El caso europeo resulta en extremo complicado, por la existencia de varios actores entre los cuales se comparte la regulación del sistema de patentes, con estructuras supranacionales en ambos casos: la EPo en el marco de la Convención Europea de Patentes, y la Unión Europea (EU) y sus instituciones, incluida la Corte Europea de Justicia. La directiva biotecnológica, Directiva 98/44/EC, transpuesta al sistema de la EPO, no transformó la autonomía funcional de la EPO, ni limita a la utilización de los mecanismos del espacio integrado de la EU. Para un estudio del tema, ver Pila, Justine y Torremans, Paul, European Intellectual Property Law, Oxford, Oxford University Press, 2016. 
de la cual ha emergido la patente europea con efecto unitario como derecho armonizado con base en la Convención Europea de Patentes (CEP) y el Tribunal Unificado de Patentes (TEUP) ${ }^{30}$, los procesos de reforma, primero, y adopción de cambios, luego, han estado acompañados de la participación de académicos en las consultas y mecanismos de participación pública de la comunidad de patentes o epistemic community ${ }^{31}$ basados en la noción de patent governance ${ }^{32}$. Patent governance se constituye como una apoyatura a la dimensión institucional y de gobernabilidad del sistema de patentes, y es un aporte de las doctrinas y construcciones teóricas de network governance o gobernanza en $\operatorname{red}^{33}$, siendo una apropiación y desarrollo de estas nociones en predios del derecho de patentes.

Shneider expone en qué ha consistido el concepto de governance en el ámbito europeo: "The new [...] mode of patent governance consists in reintroducing boundaries and constrains within patent law to restrict its expansion, and to integrate socioeconomic, regulatory, and distributive concerns into the body of the patent law" ${ }^{\text {"34 }}$. En un sentido general es positiva la lección, sin pretender reproducirla en escenarios domésticos sin validación de la requerida integración socio-económica en la regulación y actuación de los actores que operan en ese escenario.

El criterio o doctrina desarrollada por Murray y Van Zimmeren como dynamic patent governance ofrece un modelo de reformulación del sistema de patentes ${ }^{35}$. En tal sentido, propugna un modelo dinámico de gobernanza basado en el reconocimiento de actores en diversos roles, en cuyo comportamiento y relaciones fluidas se reflejan aspectos que permiten el desarrollo y evolución del sistema de patentes en la actividad de regulación, examen y concesión de la patente, y el ejercicio de la misma a diversos niveles, nacional, regional e internacional. En estos aspectos, las críticas a la funcionalidad, adaptabilidad a requerimientos y necesidades de los sectores tecnológicos en un sistema concebido como unitario, han sido permanentes. Otro aporte es la necesidad de incorporar mecanismos participatorios en el sistema de patentes ${ }^{36}$.

30 Para un estudio detallado, ver García VidAl, Á., El sistema de la patente europea con efecto unitario, Cizur Menor, Thomson Reuters-Aranzadi, 2014, pp. 57-107, 121 180; Desantes Real, Manuel, "Títulos de propiedad industrial afectados por el acuerdo sobre un Tribunal Unificado de Patentes de 2013", Actas de Derecho Industrial y Derecho de Autor, ADI, t. 35, 2014-2015, pp. 343-356.

31 Ver Murray y Van Zimmeren, Dynamic Patent Governance, cit., pp. 308-313. Ver infra, nota 57.

32 Investigadores como Drahos y Schneider, cuya producción académica aborda el enfoque de patent governance, han aportado sus criterios en estos escenarios gubernativos que proponen movimientos de reforma.

33 Por su acepción más usual, network governance. Governance, en este contexto, sería definido como: "The set of constitutive regulations that govern the interactions between the public [actors] that grant, control and rule about individual patents and their use, abuse and infringement in the market". Ver Borrás, "The Governance of the European Patent System”, cit., p. 594.

34 Schneider, I., "Can patent legislation make a difference? Bringing parliaments and civil society into patent governance", en Haunss, Sebastian y Shadlen, Kenneth C. (eds.), Politic of Intellectual Property. Contestation over the Ownership, Use, and Control of knowledge and information, Cheltenham, Edward Elgar, 2009, p. 155.

35 Ver Murray y Van Zimmeren, Dynamic Patent Governance, cit., pp. 287-342.

36 Para un estudio detallado de los mecanismos de participación, ver Murray, K., 
Para introducir elementos que propicien fluidez y dinamismo en el sistema de patentes, se valida la propuesta teórica de policy levers, concebidos como pautas o criterios de interpretación, que operan al mismo tiempo como mecanismos de creación normativa para adaptar el sistema a las exigencias de las tecnologías específicas. Los policy levers ${ }^{37}$ han sido desarrollados por autores como Lemley y Burk $^{38}$ y Van Overwalle $e^{39}$.

Patent governance propone diversos enfoques que desafían la concepción tradicional del sistema de patentes. Asimismo, propone avenidas de reinterpretación y reconfiguración del sistema y su funcionamiento vía instituciones y mecanismos normativos; en tal sentido, emplea la legislación, pero no limita la dimensión de gobernabilidad a cumplir la expresión normativista estricta de aspectos sustantivos y relaciones verticales administrativas emanadas del procedimiento.

\section{I. LA PATENTE COMO MECANISMO DE REGULACIÓN}

Ahora bien, otras aportaciones doctrinales permiten completar un marco doctrinal de patent governance. En esa dirección, se propone concebir la patente como herramienta de regulación, más que como derecho monopólico del titular reflejo de quid pro quo de divulgación a cambio de exclusividad ${ }^{40}$. Esta postura ofrece una reinterpretación de la doctrina fundacional del patent bargain, desde la que se libra al ejercicio privado la patente, cuestión de la cual han emergido sustanciales contradicciones en el ejercicio ${ }^{41}$. Considerar la patente como herramienta de regulación, pudiera pensarse, es parte de la noción que prevalece en el derecho administrativo, el cual no es el sentido de la proposición; se plantea revisar cada patente como acto de regulación.

Entre muchos otros complejos aspectos, desvelan que la regulación de patentes no se limita a la legislación, en su diseño normativo. Varios procesos o momentos de creación normativa o de regulación se suceden en los estadios de la patente. La patente no es solo el acto de concesión ${ }^{42}$, es una posición jurídica, con lo cual

"Rules for Radicals: A Politics of Patent Law", Journal of Intellectual Property Law, vol. 14, n.o 1, 2006, pp. 64-110.

37 En relación con la función, más que la definición de policy levers, plantean Burk y Lemley: "permit patent law to take account of the technology-specific nature of the patent system without inviting the rent-seeking and balkanization that specialized statutes would engender": Burk, D. L. y Lemley. M. A., The patent crisis and how the courts can solve it, Chicago y London, The University of Chicago Press, 2009, p. 95.

38 Ibíd.

39 Ver Van Overwalle, "Policy levers tailoring Patent Law", cit., pp. 436 ss.

40 Esta interpretación es presentada como resultado del estudio de Eldred en Estados Unidos. Ver Ghosh, S., "Patents and the Regulatory State: Rethinking the Patent Bargain Metaphor after Eldred", Berkeley Technology Law Journal, vol. 19, n. ${ }^{4}$, 2004, pp. 1315-1388.

41 Feldman, R., Rethinking Patent Law, Cambridge y London, Harvard University Press, 2012, pp. 9-39.

42 La concesión administrativa en la tradición continental es el acto jurídico administrativo por virtud del cual se crea la patente, es decir, el acto administrativo por el que nace y se atribuye la posición jurídica que se conoce como patente. Massaguer Fuentes, 
se aliena la propuesta con la doctrina en la materia. La patente de invención se configura como una posición jurídica ${ }^{43}$ compleja y multidimensional conformada por derechos y facultades a favor del titular, sintéticamente expuestos en la facultad de explotación en exclusiva y en el ius probibendi que impide que terceros realicen actos de explotación del objeto reivindicado con base en el alcance o ámbito de protección, y deberes correlativos de la condición de concesión administrativa para tutelar al titular de la invención ${ }^{44}$.

Con la patente se crea un derecho sobre invenciones de posibilidades inciertas de realización en el momento de su concesión y que en su iter precisa reelaborarse a sí misma. La patente genera, en sus posibilidades diferidas al futuro desarrollo de la tecnología, opciones de negociación y de ampliación de su alcance. Este aspecto se resalta en la idea de bargaining de la patente que propone Feldman ${ }^{45}$. Se adiciona ellos al ya complejo contexto en el que opera la patente.

Cada patente es un acto de regulación, en el que participan los actores involucrados, para el cual la norma jurídica ofrece el marco general. Pero dicho acto no agota todas las situaciones de valoración e interpretación que exige el examen y otorgamiento de la patente. La patente es un mecanismo regulatorio en sí mismo en relación con un objeto afinado en el cuerpo de reivindicaciones. Por lo tanto, cada patente es un esquema de regulación de potenciales posibilidades de utilización de la patente. En ese proceso de regulación, la patente excluye una tecnología de la disponibilidad para terceros, con lo cual tiene los efectos prohibitivos del ius probibendi de la patente operan con fuerza legal individualmente para cada tecnología patentada. El examen y concesión es un acto de regulación, es un proceso de creación normativa expreso o policy making process.

En otro sentido, se completa esta postura en la responsabilidad del sistema de patentes de completar sin remisiones las diversas exigencias emanadas de la regulación de la patente. Schneider expone que, en esa configuración, el sistema de patentes no puede delegar la regulación de la patente en autoridades, poderes o niveles ajenos al tradicional esquema nacional administrativo. El sistema de patentes

Los efectos de la patente, cit., pp. 37, 38.

43 En la doctrina se acoge la noción de la patente como posición jurídica. Ver Gómez Segade, J. A. y Fernández Novoa, C., La modernización del derecho de patentes, Montecorvo, Madrid, 1984, pp. 103-106, 126, 236; Vicent Chuliá, Compendio crítico de derecho mercantil, cit., pp. 654, 663; Massaguer Fuentes, Los efectos de la patente, cit., p. 37.

44 Como posición jurídica, la patente, en su acepción referida al alcance y efectos, requiere un objeto verificado en la invención reivindicada en el cuerpo, pliego o nota reivindicatoria, y el contenido expresado en el conjunto de derechos y facultades, cargas y deberes formales y sustanciales para la eficacia del título. El contenido sería en su dimensión negativa del derecho de patentes concretada en la facultad de exclusión a terceros, considerada núcleo esencial del derecho de patente, con la cual no se agota su contenido, que alcanza a la facultad de explotación de la patente que se reputa ahora en exclusiva. En resumen, se ha identificado la patente con la posición jurídica que corresponde a una persona, el inventor o su causahabiente, en la relación jurídica creada por el acto administrativo de concesión. Otero lastres, J. M.; Lema Devesa, C.; Casado Cerviño, A. y Gómez Montero, J., Comentarios a la Ley Española de Patentes, Praxis, 1987, p. 4.

45 Feldman, Rethinking Patent, cit., p. 212. 
debe ser capaz de, ex ante y expost, resolver sus conflictos, generando mecanismos de reforma ad intra y no solo remitiendo a cambios legislativos ${ }^{46}$.

\subsection{LA PATENTE COMO MECANISMO DE INTERPRETACIÓN}

Cada patente es un mecanismo o acto de interpretación de la política de patentes, para lo cual demanda criterios, pautas o presupuestos teóricos de interpretación de la norma para su aplicación a cada solicitud y patente. Los criterios de interpretación no siempre son aportados por la legislación, donde a menudo se ilustran solo premisas que demandan desarrollo, como ha ocurrido, por ejemplo, con las exigencias de moral, orden público o public ordre, e incluso con la interpretación de la patentabilidad, para lo cual no pocas autoridades han propuesto guías para ilustrar a los solicitantes, guías que han tenido considerable relevancia en el contexto normativo ${ }^{47}$.

En este aspecto ha cobrado relevancia la actuación de las autoridades en ofrecer las pautas de interpretación para determinados temas, lo que ha correspondido tanto a los tribunales como al ejecutivo, en muchos casos siendo estos a posteriori empleados por el legislador para introducir cambios legislativos.

Respecto de la interpretación que realizan los operadores en el sistema de patentes, esta debe considerarse como mecanismo y proceso, que requiere pautas y reglas en pro de la certidumbre jurídica. La interpretación es un ejercicio de poder, de autoridad, y refleja la capacidad de crear reglas mediante las cuales se despliega un ejercicio de regulación normativa, en sedes de examen y concesión y en la revisión judicial o por estructuras $a d h o c^{48}$. No puede, por ende, librarse al arbitrio de los operadores. Se ilustra este aspecto en la interpretación de la solicitud, donde un ejercicio implícito de abstracción tiene lugar en extremos como definir la materia patentable de la solicitud en los parámetros legales y su carácter técnico sin discriminar sector tecnológico, evaluar los requisitos positivos sustantivos de patentabilidad, o determinar el alcance de la protección previsto por las reivindicaciones. Como viene siendo práctica, en el examen las autoridades entablan comunicación con el solicitante para definir aspectos relevantes de la solicitud, donde solicitante y examinador interactúan y negocian el objeto de la patente. Quizás lo que deba cambiarse es el carácter vertical de este proceso, debiendo el comportamiento de las autoridades evolucionar hacia la colaboración. El basamento estático apoyado en la jerarquía de la Administración puede atentar contra el propio sistema y su

46 Schneider, "Can patent legislation", cit., p. 154.

47 La práctica de linemientos, directrices de patentabilidad, ha sido reflejo de la intepretación en el sistema de patentes, y de la capacidad de producción normativa de las autoridades de examen. Siguiendo la lógica expuesta, operan como mecanismos de regulación.

48 Ver SCHNeIder, I. "Governing the patent system in Europe: the EPO's supranational autonomy and its need for a regulatory perspective", Science and Public Policy, vol. 36, n. ${ }^{\circ} 8$, pp. 619-629. 
funcionamiento; es preciso asimismo establecer, con mayor alcance, mecanismos legales de restablecimiento y restitución de derechos, a nombre de los beneficios que la patente ofrece y de los fundamentos del sistema.

Mediante los mecanismos provistos por la dimensión de gobernanza y el patent governance como objeto de revisión teórica de la patente, puede afirmarse que el sistema de patentes y el derecho de patentes han evolucionado, asimilando modificaciones sustanciales sustantivas, $y$ han adaptado sus exigencias al desarrollo tecnológico, como corresponde a un sistema unitario y neutral en relación con las tecnologías patentables.

\subsection{El sistema de patentes unitario y la adaptación a teCNOlogías. POLICY LEVERS}

El sistema de patentes se ha mantenido, respecto a las tecnologías protegidas, como unitario, neutral y uniforme ${ }^{49}$. A ello responden el diseño normativo y los estándares para proteger a las invenciones en cualquier campo o sector de la tecnología con base en su carácter técnico. Esta característica se refleja en el principio de no discriminación por sector de la tecnología ${ }^{50}$. La dimensión de gobernanza, como se aprecia, refuerza o bien pone en riesgo este equilibrio del sistema, con la labor de adaptación a las tecnologías. Nótese que el calificativo de unitario y uniforme no refiere a las estructuras o parámetros de funcionamiento, sino a los criterios de valoración de la materia patentable de forma que cubra todas las tecnologías, y la aplicación a estas de los criterios o estándares sustantivos de patentabilidad.

En el ajuste a las necesidades de las tecnologías, la identificación y puesta en aplicación de policy levers ha aportado a la adaptabilidad del sistema de patentes a las exigencias de los sectores tecnológicos emergentes. Los policy levers como operaciones de interpretación y de regulación han permitido el encuadre de ciertas tecnologías en la protección mediante patentes.

Los policy levers aportan elementos valorativos de diversa índole. Tienen diferente ratio y distintos escenarios donde operar, procedentes de la actividad interpretativa de las autoridades de examen y concesión o de los tribunales. Entre otros, se han definido reglas para interpretar la patentabilidad, el concepto de materia patentable y descubrimiento, moralidad, orden público, alcance de la patente y las doctrinas como la de los equivalentes o las reivindicaciones tipo Swiss y fórmulas Markush, los requisitos para conceder licencias obligatorias. Los policy levers reflejan las valoraciones que complementan el significado de la regulación de esos aspectos en la norma y se han volcado a directrices o lineamientos de patentabilidad ${ }^{51}$.

49 Ver Burk y Lemley, The patent crisis, cit., pp. 3-35.

50 Acuerdo trips, art. 27.1. Para un análisis detallado del principio, ver Malbon, Lawson y Davison, The wto Agreement, cit., pp. 410-418.

51 Un criterio clasificatorio de los policy levers es aportado por Van Overwalle, colocándolos en diferentes bloques en función del nivel de adopción, nacional, regional o internacional, y del origen de creación y empelo, ejecutivo administrativo, judicial o 
De hecho, la adecuación del sistema de patentes, unitario y uniforme, a las necesidades y caracteres de sectores tecnológicos emergentes se ha originado a partir de la interpretación y de los policy levers. En muchos casos no han necesitado de cambios o modificaciones sustantivas, lo que permite afirmar que las relaciones de gobernanza han iniciado cambios relevantes en la protección y otorgamiento de patentes, en clara manifestación de que el sistema de patentes enfrenta en su funcionamiento las demandas y necesidades específicas de los sectores tecnológicos, en su readecuación a sus criterios sustantivos, y al principio de no discriminación, ante nuevas solicitudes de patentabilidad de tecnologías emergentes.

\section{Actores del sistema de patente. Valoraciones de SU Repercusión EN LA DIMENSIÓN INSTITUCIONAL Y DE GOBERNANZA}

Un aspecto cardinal de la gobernanza queda determinado por los actores y las relaciones que se establecen entre estos. A lo largo del artículo hemos distinguido entre sujetos, operadores, y actores del sistema y derecho de patentes. En este apartado se expone cómo la centralidad del sistema de patentes ha sido modificada en capítulos recientes, y los desafíos que esta cuestión genera a la tradicional visión de un sistema ordenado en torno a relaciones jerárquicas lideradas por la Administración nacional con funciones de examen y concesión.

Anticipando el panorama gestado, debe decirse que la posición de los actores formales del sistema de patentes en su monopolio regulatorio ha sido modificada y sustraída por otros actores formales, que comparten funciones y roles afines respecto de la patente, así como han emergido actores informales con incidencia en la adopción de políticas en temas vinculados, como la salud, el desarrollo sostenible y el medio ambiente, la transferencia de tecnología, los recursos biológicos y genéticos, los derechos humanos, el patrimonio cultural, por mencionar algunos de los más relevantes. El tema que más aflora son las relaciones entre patentes biotecnológicas, acceso a medicamentos y salud pública, siendo un terreno de alto nivel de conflictividad y especialización. Pero también ha ocurrido en el derecho de la competencia, con conductas de los titulares de patentes que han sido calificadas de anticompetitivas ${ }^{52}$.

El criterio de dynamic patent governance refleja la apertura en la actuación de personificaciones administrativas diversas, y de otros externos a las tradicionales relaciones en el sistema de patentes en manifestación de sus vínculos con autoridades externas, además de los niveles diferentes en que la patente se regula y opera, a saber, las interacciones entre los derechos nacionales, regionales y el derecho internacio-

normativo. Su criterio los ubica en las etapas de existencia, pre grant, y de ejercicio o post grant. Ver Van Overwalle, "Policy Levers Tailoring Patent Law", cit., pp. 435-517.

52 Para un estudio detallado, ver Uribe Piedrahíta, Carlos A. y Carbajo Cascón, Fernando, "Regulación ex ante y control ex post: la difícil relación entre propiedad intelectual y derecho de la competencia", Actas de Derecho Industrial y Derecho de Autor (ADI), 33, 2012-2013, pp. 307-330. 
nal. Propone, en principio, más que poner nombre a los actores, evaluar los roles $\mathrm{y}$ funciones que desempeñan en un sistema concreto, para que sirva de modelo teórico de evaluación en cualquier sistema nacional y ordenamiento jurídico ${ }^{53}$.

Debe señalarse que la patente no opera en un único escenario administrativo, realidad que cuestiona la tradicional relación Administración-administrado (solicitante y/o titular). El sistema de patentes se ha convertido en un multilevel system, que reconoce en su diseño los distintos niveles de regulación, nacional, regional e internacional, y sus relaciones en razón de cuestiones técnico-jurídicas. En la actividad de examen y concesión, varios actores resultan involucrados cuando un solicitante moviliza el mecanismo PCT o el mecanismos de la EPO, con los que defiere a una autoridad diferente que opera como actor, para dar paso a otro actor que desempeña un rol concesional garante de la eficacia territorial del título conferido ${ }^{54}$.

La relación entre el sistema internacional y los ordenamientos nacionales revela que el sistema de patentes opera en múltiples escenarios, administrativos e intergubernamentales, liderados por actores formales, de acuerdo con el contenido de las obligaciones jurídicas internacionales peculiarmente diseñadas en el Acuerdo TRIPS $^{55}$. De igual forma dan participación a actores informales, como ongs, pueblos originarios y naciones ${ }^{56}$. Estos han sido bautizados como epistemic community ${ }^{57}$. En tal sentido, se observan las notas de un régimen internacional de las patentes, que alcanza a la propiedad intelectual en general.

Finalmente, la incidencia de la regulación regional no es menos relevante si se considera que ha motivado parte de las profundas modificaciones de gobernanza que se han gestado en los últimos años ${ }^{58}$.

53 Ver Murray y Van Zimmeren, Dynamic Patent Governance, cit., p. 295.

54 Los sistemas nacionales de patentes coexisten con otros mecanismos de origen supranacional y regional en los que se desplaza la función de autoridad de examen a una instancia externa, pudiendo ser una agencia nacional, una autoridad nacional de otro país, o una organización supranacional regional. En estos casos, el procedimiento de examen es compartido entre autoridades. Se puede calificar como un mecanismo o procedimiento híbrido o compartido. En el caso de los modelos regionales, se implementa un modelo bifurcado entre autoridades en la Decisión 486 de la CAN.

55 Ver supra, nota 2.

56 Esto ha ocurrido en sede de patentes, en temas tan sensibles como la protección de los conocimientos tradicionales, en denuncia de no pocas prácticas de biopiratería o cognopiratería. Las organizaciones internacionales han dado participación activa en foros intergubernamentales, que en cuanto a su alcance teórico los dota de ciertos elementos de personalidad jurídica en el derecho internacional. Ver Guevara Fernández, ErnesTO, "Conocimientos tradicionales, propiedad intelectual y negociaciones internacionales: ¿gestación de nuevos derechos?”, Propiedad Intelectual, año 11, n.o 15, enero-diciembre 2012, pp. 204-226.

57 Como epistemic community se considera a los expertos, académicos, abogados de patentes, jueces, ONGs, ordenadas para valorar los desafíos de la patentabilidad, desde enfoques éticos y colectivos. Ver Murray y Van Zimmeren, Dynamic Patent Governance, cit., pp. 308-313; Schneider, “Governing the patent”, cit., pp. 619-622.

58 El caso europeo, o el caso de la Comunidad Andina (CAN) son ilustrativos de un panorama de regulación sustantiva y de instauración de niveles de gobernanza del sistema común y supranacional como partes de esquemas de integración regional. 


\section{I. ACtores formales del Sistema. ACtOres PRimarios y SECUNDARIOS DEL SISTEMA}

Los actores formales primarios tienen a su cargo funciones regulatorias sobre el sistema de patentes. En estas se sostiene la propuesta y adopción de políticas públicas y de decisiones normativas y administrativas. Legislador, esfera judicial y Administración de patentes son los principales actores formales primarios o directos. Revelan la estructura vertebradora de la dimensión institucional, sobre la que se sostiene cualquier modelo adoptado. En este caso, la variedad de tribunales en los distintos procesos diversifica la producción de fallos y criterios. En el caso del legislador, su rol circunstancial ha abierto paso a que sean asumidos procesos por el ejecutivo, e incluso, como se ha ilustrado, a que la función de regulación normativa se refleje en decisiones de las autoridades de examen en forma de lineamientos o directrices de patentabilidad, combinando regulación e interpretación de los criterios legales con base en la práctica y las realidades de la patentabilidad ${ }^{59}$.

Los actores formales secundarios son autoridades especializadas, externas a las oficinas de patentes. Cuentan con sus propios regímenes y áreas de regulación, donde operan como expertos. Los casos más relevantes son los de autoridades de competencia, sanitarias, de medicamentos y productos farmacéuticos, de estandarización y normalización, o los de autoridades de autorización para inversión extranjera. Asumen funciones replicativas, o de expertos. E introducen desafíos a la dimensión de ejercicio del derecho de patentes.

Sobre la base de estos elementos resulta oportuno un paréntesis para abordar el tema de la gobernanza del sistema de patentes centrada en una autoridad nacional de examen y concesión. El sistema de patentes se ha sostenido en una autoridad central, angular, de la Administración para comprobarlas exigencias tipificadas, es rezago de modelos estáticos de patentes. No pocas críticas se han volcado sobre la actuación de la autoridad administrativa de examen que son sometidos a escrutinio. La patente se manifiesta como un mecanismo de repercusiones singulares, que ha dejado de ser de interés exclusivo de la autoridad de examen y concesión. En relación con el examen y el funcionamiento, las oficinas enfrentan problemas con los recursos humanos y el cumplimiento de términos, redundando en la calidad de las patentes, expertos suficientes y con el nivel requerido y en número suficiente para valorar los requisitos de patentabilidad, la calidad de exámenes y el otorgamiento de patentes fuertes.

En la evaluación de requerimientos de patentabilidad, los excesivos mecanismos administrativos de subordinación, que impone la autoridad administrativa

59 Murray y Van Zimmeren, Dynamic Patent Governance, cit., pp. 295-297, 313-315. La doctrina "administrative framework and heterogeneity framework" ha sido analizada por Kali Murray, basándose en casos como Chevron y sus precedentes en el contexto jurisprudencial de Estados Unidos. Ver Murray, K., "The Cooperation of Many Minds: Domestic Patent Reform in a Heterogeneous Regime”, IDEA: The Intellectual Property Law Review, vol. 48, 2008, pp. 289 ss. 
al solicitante y a los terceros para su participación en procedimientos y recursos, atentan contra el funcionamiento del sistema y los fines últimos que promueve. La patente, nacida del acto concesional, interesa a la sociedad en su conjunto, cuestión que no puede perder de vista el legislador ni la autoridad de examen y concesión. Resulta atinado que la Administración ordene el procedimiento, pero no debe desconocer que se trata de un aporte tecnológico a la sociedad para el que se solicita protección que su intervención valida e incorpora al acervo colectivo, y no como una movilización del sistema para obtener un favor o gracia de la Administración. En tal sentido, el legislador y, en labor garantista, los tribunales deben valorar las actuaciones de la Administración de patentes, en un terreno donde el carácter discrecional de su actuación debe reglarse. Ello se lograría con apropiados mecanismos de restablecimiento de derechos y plazos razonables para responder los requerimientos entablados en el examen sustantivo, cuestiones que, por demás, no son el corpus, sino aspectos formales, por lo general, subsanables. Este aspecto ha encontrado construcción doctrinal con base en el reconocimiento de derecho a la patente en cabeza del inventor ${ }^{60}$. Sin negar y combinándolo con el carácter constitutivo del derecho cuando se constituye en sede administrativa concesional ${ }^{61}$, brinda un referente valioso de perfeccionamiento del sistema de patentes en este acápite.

La actuación de las autoridades de patentes se ha calificado de tecnocrática. Si bien la especialización reclama niveles de experticia en el tema, independencia y autonomía funcional, autodeterminación, comportamiento autorreferencial, en otros casos se han manifestado deformaciones en el funcionamiento de las oficinas de patentes. Entre las deformaciones que se observan en el comportamiento de las autoridades se señala en los estrictos y cerrados los mecanismos de participación, su actuación como autoridad auto normativa, la labor auto asignada de diseño de políticas públicas en materia de patentes que corresponde a otros actores, y el clientelismo o regulatory capture por intereses de los usuarios, en nombre del interés público ${ }^{62}$.

Retornando a los cauces del reconocimiento de nuevos y heterogéneos actores institucionales, públicos, privados o ad hoc, debe señalarse que estos actores pueden devenir contendientes y sustraer facultades a los actores principales. Los actores formales secundarios desempeñan un rol, cuando la patente, concedida, demanda de correcciones en casos de prácticas que se califiquen como lesivas a

60 En la literatura se desarrolla esta noción por autores como Zuccherino. Ver ZucCherino, Daniel, Patentes de invención: introducción al estudio de su régimen legal, Buenos Aires, Ad-Hoc, 1998. En sentido contrario en el mismo sistema jurídico, ver Correa, Carlos M.; Bergel, Salvador D. y Kors, Jorge, Régimen legal de las patentes de invención, t. I, Buenos Aires, La Ley, 2013.

61 Bensadon expone: "la titularidad del invento se acredita con el otorgamiento de un título por parte de la Administración. Sin embargo, el derecho en sí no es otorgado sino reconocido. Lo que otorga la Administración es el título, no el derecho". Bensadon, Martín, Derecho de patentes, Buenos Aires, Abeledo-Perrot, 2012, p. 21.

62 Schneider, "Governing the patent", cit., pp. 619-621. 
la competencia, por las autoridades de derecho de la competencia, o en casos en que autorizaciones adicionales sean exigidas por los ordenamientos, como en la comercialización de medicamentos y productos farmacéuticos.

\subsection{INVENTORES, SOLICITANTES Y TITULARES}

En un sistema destinado a otorgar posiciones jurídicas de explotación en exclusiva, los destinatarios principales para adquirir los títulos legales requieren una consideración particular por varios motivos: primero, son los destinatarios de la regulación, y segundo, una vez concedida la patente, son los principales legatarios de las funciones reconocidas a las patentes como incentivo y vector del desarrollo económico.

Los inventores acuden al sistema de patentes en busca de protección de sus creaciones intelectuales. La organización de las actividades de $\mathrm{I}+\mathrm{D}+\mathrm{i}(\mathrm{R} \& \mathrm{D})$ que permiten obtener patentes, en muchos casos determina los comportamientos al requerir la protección. Entre otros elementos, obedece el comportamiento al tipo de tecnología, al financiamiento de las actividades de R\&D, y a las capacidades de explotación, por sí, o por terceros mediante estrategias de licenciamiento de las patentes, entre muchos otros.

Entre solicitantes y examinadores se entabla un proceso de negociación del alcance de la patente fijado por su objeto en las reivindicaciones. En este diálogo, desde la presentación de la solicitud y a lo largo del procedimiento de examen, se ejerce presión y poder sobre las autoridades de examen, lo que se ha calificado como clientelismo ${ }^{63}$. El clientelismo se agudiza por la filiación del solicitante, siendo más fuerte cuando se trata de multinacionales o empresas con portafolios numerosos de patentes, que indican cierto juego de poder que viene ocurriendo en el sistema de patentes ${ }^{64}$. En no pocos casos las autoridades de examen sucumben ante las demandas de protección, o adoptan criterios interpretativos referenciales que introducen cambios en el examen de patentabilidad.

El criterio empírico de catalogación es el de las preferencias y efectos en la protección de la tecnología en cuestión. Es posible diferenciar entre los intereses de solicitantes individuales, universidades públicas, centros públicos de investigación, que apuestan por patentes sólidas y respetan las reglas del sistema. En el caso de los empresarios, los sectores tecnológicos, el tipo de tecnología y de mercados en que se desenvuelven, las dimensiones o magnitud de sus activos empresariales en relación con su condición de grandes o pequeñas empresas, son los que definen la diversidad de comportamientos de estos actores ${ }^{65}$.

63 Ibíd., p. 620.

64 Se analiza la incidencia de las multinacionales en el sistema de patentes, y las relaciones de poder que han acompañado al sistema de patentes. Ver Drahos, The global governance..., cit., pp. 3-5, 7-18.

65 Kesan, J. y Gallo, A., "The Political Economy of the Patent System", North Carolina Law Review, vol. 87, n.o 5, 2009, pp. 1341, 1352-1354. 
En otros casos, ex post, se presentan al sistema de patentes desafíos expresados en conductas de diverso origen de los titulares de las patentes: estrategias de explotación de derechos concedidos y formación de patent thickets y patent trolls ${ }^{66}$; solicitud fraudulenta de derechos y extensión de la validez de las patentes concedidas ${ }^{67}$; negativas de conceder licencias contractuales voluntarias; abuso de posición dominante en el mercado tecnológico concreto. En general, estas conductas en el ejercicio de los derechos por sus titulares requieren de la intervención legalmente reservada a las autoridades tradicionales por medio de mecanismos y herramientas que forman parte del régimen jurídico-público de la patente como las licencias obligatorias. En muchos casos posibilitan la intervención de autoridades externas al sistema de patentes cuando califican como conductas o prácticas anticompetitivas y se aplica el régimen de derecho de la competencia, como ocurre con la posición dominante y su abuso, y con las distorsiones al mercado y los consumidores.

\subsection{Actores informales}

En el caso de los actores informales, se considera en el estudio de casos como Myriad, la emergencia y maduración de una comunidad interesada en decisiones de política de patentes, epistemic community ${ }^{68}$ de expertos, jueces, ONGs, han demandado y accionado para lograr un funcionamiento de mínimos que mantenga los equilibrios del sistema de patentes ${ }^{69}$.

Este panorama de actores heterogéneos demanda que el enfoque de los actores en el diseño institucional del sistema de patentes se enfoque en los roles asumidos o funciones desempeñadas, más que en la nomenclatura o posición de los actores sobre la base de vínculos jerárquicos.

\subsection{REDiseñar LAS RELACIONES ENTRE LOS ACTORES Y LOS MECANISMOS DE PARTICIPACIÓN}

En sectores académicos viene distinguiéndose entre Administración pública, gestión pública (public management) y gobernanza (collaborative governance), en

66 Shapiro, Carl, "Navigating the Patent Thicket: Cross Licenses, Patent Pools, and Standard-Setting”, en JAffe, A. et al. (eds.), Innovation Policy and the Economy, Massachusetts, mit Press, 2001, pp. 119-150. Martínez Pérez, M., "Los patent thickets y los patent trolls: análisis desde la perspectiva europea”, en García Vidal, Ángel (dir.), Patentes farmacéuticas y derecho de la competencia, Thomson Reuters-Aranzadi, Cizur Menor, 2015, pp. 67-100. Van Overwalle, G., "Of Thickets, Blocks and Gaps: Designing Tools to Resolve Obstacles in the Gene Patents Landscape”, en Van Overwalle, G. (ed.), Gene Patents and Collaborative Licensing Models. Patent Pools, Clearing Houses, Open Source Models and Liability Regimes, Cambridge, Cambridge University Press, 2009, pp. 381-463.

67 García Vidal, Ángel, "El derecho de la competencia y la solicitud fradulenta de patentes y de certificados complementarios de protección de patentes”, en GARCía VIDAL (dir.), Patentes farmacéuticas, cit., pp. 31-66.

68 Ver supra notas 31 y 57.

69 Murray y Van Zimmeren, Dynamic Patent Governance, cit., pp. 308-313. 
su aplicación a las relaciones público-privadas que son propias del sistema de patentes ${ }^{70}$. De igual forma, se abre paso la noción de buena administración, que favorece la adaptabilidad a los retos relacionales del sistema ${ }^{71}$. Governance implica regular negociando, mediante cuestiones colaborativas, en modelos de regulationby-negotiation ${ }^{72}$. Bingham, comentando a Freeman, considera que el derecho administrativo deberá reorientarse facilitando la efectividad de los regímenes de regulación público-privados, abandonando en estos el diseño de relaciones constreñidas a la actuación discrecional de la autoridad representante de la Administración.

Dynamic governance propone la articulación de relaciones fluidas entre los diferentes actores. Para ello, el primer punto será reconocer que la presencia de actores heterogéneos es un hecho en los sistemas de patentes y que se convierte en un desafío al sistema de patentes estático o tradicional prevaleciente en los ordenamientos jurídicos nacionales.

Como se ha apuntado, las relaciones horizontales entre los actores del sistema de patentes, en un marco de reconocimiento y legitimación, deben complementar y aun desplazar a las relaciones jerárquicas verticales. En el sistema de patentes nacional ordenado por la soberanía estatal y la territorialidad, y por un título y posición jurídica emanado de la actuación concesional con carácter constitutivo como es la patente, no serán desplazados ni afectados estos criterios vertebradores por la promoción de un escenario colaborativo de relaciones fluidas entre actores formales primarios y secundarios, y entre estos y los actores informales. Además, debe considerarse que la armonización, convergencia e internacionalización de la gobernanza atenta contra la eficiencia de un sistema fragmentado de escenarios territoriales incomunicados sobre el que solo se podrá sostener un sistema estático. Ello es válido incluso en el propio ordenamiento jurídico cuando no se reconocen las relaciones entre autoridades de competencia y sanitarias, basándose en relaciones jurídico-administrativas ordenadas por autoridades de examen y concesión incólumes a los desafíos de sus escenarios. Tal comportamiento atentaría contra la eficiencia y funcionalidad, que sería entonces difusa y capturada, y no cumpliría a cabalidad con fines últimos superiores como son la promoción del desarrollo y el progreso y el fomento de la innovación.

Los mecanismos de participación en el sistema de patentes serían el elemento de cierre de la dimensión de gobernanza. En tal sentido se han venido ofreciendo estudios de los mecanismos de participación, tanto en los procedimientos, como de terceros $^{73}$. En el escenario de las autoridades administrativas se ensayan mecanismos

70 Bingham, Lisa, "Collaborative Governance", Journal of Dispute Resolution, vol. 2009, n.o 2, 2009, p. 276.

71 Ver Rodríguez-Arana Muñoz, Jaime, El buen gobierno y la buena administración de instituciones públicas, Cizur Menor, Thomson-Aranzadi, 2006.

72 Ver Funk, William, "Bargaining Toward the New Millennium: Regulatory Negotiation and the Subversion of the Public Interest", Duke Law Journal, vol. 46, 1997, pp. 1351-1388.

73 Para un estudio detallado de los mecanismos de participación, ver Murray, K., "Rules for Radicals: A Politics of Patent Law", Journal of Intellectual Property Law, vol. 14 , n. ${ }^{\circ} 1$, 2006, pp. 64-110. 
para ampliar mecanismos institucionalizados de acceso de terceras partes de las decisiones administrativas, y la colaboración con actores especializados en el diseño de políticas de interés común, uniformando las salidas de los regímenes. En otro sentido, en las reformas al sistema de patentes se postula su escasa democratización, lo cual se enfrentará con la introducción de mecanismos participativos. Entre estos se encuentran: procedimientos en las etapas de la vida de la patente; la ampliación de la publicación; la precisión al público y terceras partes de los estados legales y estadios de integridad; acceso a expedientes, opiniones de examinadores; la fundamentación de las decisiones en los instrumentos administrativos; la introducción de mecanismos informales orientados a la transparencia como blogs oficiales ${ }^{74} \mathrm{o}$ casos como Ombudsman Pilot Program ${ }^{75}$.

En la dimensión de gobernanza del sistema de patentes, institucional y de funcionamiento del sistema, el dinamismo del sistema a partir del reconocimiento de actores, formales e informales, permite establecer relaciones de nuevo tipo. Los actores ofrecen las esferas formal e informal de gobernanza del régimen jurídico de patentes. La dinamización del sistema de patentes permite la reinterpretación y renovación de los mecanismos de intervención pública, reservados a los actores en las diversas etapas del iter del derecho de patentes, ante situaciones propias de la vida de la patente y su desempeño eficiente en el tráfico jurídico.

\section{A MOdo DE CONCLUSIONES}

El criterio de gobernanza como dimensión en el sistema de patentes implica, y esto es esencial, movilizar todos los mecanismos del sistema previstos en la dimensión pública, en su régimen jurídico público, y para lograr el funcionamiento óptimo del sistema de patentes. Equilibrado con la dimensión privada de ejercicio, propondrá un sistema adaptable a las realidades de los sistemas de patente. Un modelo de patent governance debe asentarse y proyectarse desde las dimensiones del sistema de patentes, brindando los elementos referenciales de la manera como debe operar en su entramado de herramientas y mecanismos propios, y en sus relaciones con actores en el contexto en que la patente opera. El sistema de patentes cuenta con sus propias herramientas para garantizar su funcionamiento, pero debe emplearlas en el ámbito del rediseño y reinterpretación del rol de sus instituciones y en encaminarlas al funcionamiento del sistema.

La gobernanza incide, define, condiciona la dimensión pública del sistema de patentes, expresada en la intervención pública como criterio ordinal de seguridad jurídica en el ordenamiento y cumplimiento de sus fines últimos. Esta interacción

74 Director's Forum, David Kappos' Public Blog, U.S. Patent \& Trademark Office, disponible en: http://www.uspto.gov/blog/ President's Blog, European Patent Office, disponible en: http://blog.epo.org/?banner=homepage (último acceso, mayo de 2017).

75 Ombudsman Pilot Program, U.S. Patent \& Trademark Office, disponible en: http:// www.uspto.gov/patents/ombudsman.jsp (último acceso, mayo de 2017). 
y por ende su revisión en los ordenamientos jurídicos, ofrece potencialidades para que se garantice el balance de intereses públicos y privados que preside el sistema de patentes.

Un sistema de patentes dinámico, que haga posible el reconocimiento formal y la interacción fluida y funcional entre actores de acuerdo con sus roles, asumiendo a la patente como un complejo proceso de regulación normativa, de interpretación y aplicación, por medio de criterios pivotales o policy levers de adaptación al desafío tecnológico, permitirá un enfoque teórico sobre el sistema de patentes que brinde oportunidades de perfeccionamiento en las actuales coyunturas.

El funcionamiento del sistema de patentes tiene tanto de jurídico como de político. Y no en referencia exclusivamente a las decisiones políticas que involucran y reflejan los intereses de los Estados y sus gobiernos, sino también por la presencia de actores heterogéneos, como transnacionales y sector empresarial. El sistema de patentes, como forma de otorgar posiciones monopólicas privilegiadas por medio de las herramientas que brinda el derecho, es un ejercicio de management, de administración, y de governance, en su más directo sentido jurídico de realización. La conducción del sistema de patentes corresponderá a autoridades de la Administración Pública, en representación del Estado, como se entiende en el diseño primigenio y en la realización actual del sistema de tutela, que deben reconocer los complejos desafíos a su actividad, y ser receptivas, desarrollando su capacidad de respuesta a los desafíos de la innovación, la industria y los actores.

En sede negocial, contractual y de transferencia de tecnología y diseminación del conocimiento, la posición jurídica en que se constituyen la patentes encuentra interesantes capítulos en el diseño de estrategias de gestión y comercialización por los titulares de las patentes, donde el papel del derecho y el del sistema de patentes son retados por estrategias de patentamiento, explotación, de asociación y comercialización, todas con alto grado de complejidad en los escenarios actuales, en sectores como la biotecnología, o mejoramiento vegetal, la salud humana y animal, entre otros. Frente a esos desafíos, patent tickets, patent trolls, la gobernanza del sistema resulta clave en el logro de la eficiencia del sistema y el cumplimiento de los fines y fundamentos iusfilosóficos y económicos que justifican la existencia de las patentes y que movilizan al aparato estatal para su concesión.

A ellas deberá responder el sistema de patentes. 


\section{BibLIOGRAFÍA}

Bercovitz Rodríguez-Cano, Alberto (dir.), La nueva Ley de Patente. Ley 24/2015, de 24 de julio, Cizur Menor, Thomson Reuters-Aranzadi, x2015.

Borrás, S., "The Governance of the European Patent System: Effective and Legitimate", Journal Economy and Society, vol. 35, n. ${ }^{\circ} 4,2006$.

Burk, D. L. y Lemley. M. A., The patent crisis and how the courts can solve it, Chicago y London, The University of Chicago Press, 2009.

Burris, S.; Drahos, P. y Shearing, C., "Nodal Governance", Australian Journal of Legal Philosophy, vol. 30, 2005.

Cabanellas de las Cuevas, Guillermo, Derecho de las patentes de invención, 2. ${ }^{\text {a }}$ ed., Heliasta, Buenos Aires, 2004.

Conde Gallego, Beatriz, "La política de competencia en el sector farmacéutico: nuevos desafíos para la relación entre los derechos de propiedad industrial y el derecho de competencia", Actas de Derecho Industrial y Derecho de autor (ADI), 31, 2010-2011, pp. 55 ss.

Correa, Carlos M., Acuerdo triPs. Régimen internacional de la propiedad intelectual, Buenos Aires, Ciudad Argentina, 1998.

Correa, Carlos M.; Bergel, Salvador D. y Kors, Jorge, Régimen legal de las patentes de invención, Buenos Aires, La Ley, 2013.

Curto Polo, Mercedes, "La patentabilidad de las secuencias genéticas en Estados Unidos de América tras la Sentencia del Tribunal Supremo en el asunto 'Association for Molecular Pathology et al. v. Myriad Genetics Inc, et al.' y la incidencia de este pronunciamiento judicial en el ámbito europeo", Actas de Derecho Industrial y Derecho de autor (ADI), 34, 2013-2014, pp. 493-517.

Curto Polo, Mercedes, "Algunas novedades en relación con la materia patentable en los Estados Unidos de América", Actas de Derecho Industrial y Derecho de autor (ADI), 35, 2014-2015, pp. 25-42.

Desantes Real, Manuel, "Títulos de propiedad industrial afectados por el acuerdo sobre un Tribunal Unificado de Patentes de 2013", Actas de Derecho Industrial y Derecho de Autor, ADI, t. 35, 2014-2015, pp. 343-356.

Drahos, Peter, A Philosophy of Intellectual Property, Burlington, Dartmouth Publishing Company, Alderhorst, 1996, reimp. 2001.

Drahos, Peter, The global governance of knowledge. Patent Offices and their clients, Cambridge University Press, Cambridge y New York, 2010.

Feldman, Robin, Rethinking Patent Law, Cambridge y London, Harvard University Press, 2012.

Fernández-Novoa, Carlos; Otero Lastres, J. M. y Botana Agra, M. J., Manual de la propiedad industrial, 2. ${ }^{a}$ ed., Madrid, Marcial Pons, 2013.

Fernández Rodríguez, Carmen, Propiedad industrial, propiedad intelectual y derecho administrativo, Madrid, Dykinson, 1999. 
García Vidal, Ángel (dir.), Patentes farmacéuticas y derecho de la competencia, Cizur Menor, Thomson Reuters-Aranzadi, 2015.

García Vidal, Á., El sistema de la patente europea con efecto unitario, Cizur Menor, Thomson Reuters-Aranzadi, 2014.

Gómez Segade, José Antonio, Tecnología y derecho, Madrid, Marcial Pons, 2000. Grosh, S., "Patents and the Regulatory State: Rethinking the Patent Bargain Metaphor after Eldred", Berkeley Technology Law Journal, vol. 19, n. ${ }^{\circ} 4,2004$, pp. 1315-1388.

Kesan, J. y Gallo, A., "The Political Economy of the Patent System”, N.C. L. Rev., 87, 2009, pp. 1352-1354.

Malbon, Justin; Lawson, Charles y Davison, Mark, The wto Agreement on Trade-Related Aspects of Intellectual Property Rights: A commentary, Edward Elgar, Cheltenham, 2014.

Martín Aresti, Pilar, La licencia contractual de la patente, Pamplona, Aranzadi, 1997.

Martín Aresti, Pilar, "Capítulo 15. Derecho antitrust y protección de los bienes inmateriales", en García-Cruces, J. A. (coord.), Tratado de derecho de la competencia y de la publicidad, vol. 1, Valencia, Tirant lo Blanch, 2014.

Martín Aresti, Pilar, "Capítulo xv. Transferencias, licencias y gravámenes", en Bercovitz Rodríguez-Cano, Alberto (dir.), La nueva Ley de Patente. Ley 24/2015, de 24 de julio, Cizur Menor, Thomson Reuters-Aranzadi, 2015, pp. 347-383.

Massaguer Fuentes, J., Los efectos de la patente en el comercio internacional, Barcelona, Bosch, 1989.

Murray, K. y Van Zimmeren, E., Dynamic Patent Governance in Europe and the United States: The Myriad Example, Marquette University Law School, Marquette Law Scholarly Commons Faculty Publications, 2011, pp. 287-342.

Murray, K., "The Cooperation of Many Minds: Domestic Patent Reform in a Heterogeneous Regime", IDEA: The Intellectual Property Law Review, vol. 48, 2008, pp. 289 ss.

Murray, K., "Rules for Radicals: A Politics of Patent Law", Journal of Intellectual Property Law, vol. 14, n. ${ }^{\circ}$ 1, 2006, pp. 64-110.

Schneider, I., "Governing the patent system in Europe: The EPo's supranational autonomy and its need for a regulatory perspective", Science and Public Policy, vol. 36, n. ${ }^{\circ}$ 8, pp. 619-629.

Schneider, I., "Can patent legislation make a difference? Bringing parliaments and civil society into patent governance", en Haunss, Sebastian y Shadlen, Kenneth C. (eds.), Politic of Intellectual Property. Contestation over the Ownership, Use, and Control of knowledge and information, Cheltenham, Edward Elgar, 2009. 
Shapiro, Carl, "Navigating the Patent Thicket: Cross Licenses, Patent Pools, and Standard-Setting", en Jaffe, Adam et al. (eds.), 7 Innovation Policy and the Economy, Massachusetts, MIT Press, 2001, pp. 119-150.

Uribe Piedrahita, Carlos A. y Carbajo Cascón, F., "Regulación ex ante y control ex post. la difícil relación entre propiedad intelectual y derecho de la competencia", Actas de Derecho Industrial y Derecho de autor (ADI), 33, 20122013, pp. 307-330.

Van Overwalle, G. (ed.), Gene Patents and Collaborative Licensing Models. Patent Pools, Clearing Houses, Open Source Models and Liability Regimes, Cambridge, Cambridge University Press, 2009.

Van Overwalle, G., "Policy Levers Tailoring Patent Law to Biotechnology: Comparing U.S. and European Approaches", UC Irvine Law Review, vol. 1, n. ${ }^{\circ} 2,2011$, pp. $435-517$. 